\title{
DIRETOR DE ESCOLA: DIFICULDADES E ENFRENTAMENTOS
}

\author{
SCHOOL PRINCIPAL: DIFFICULTIES AND FACES \\ DIRECTOR DE ESCUELA: DIFICULTADES Y ENFRENTAMIENTOS
}

Fernanda Santos de Góes Araújo E-mail: araujofernanda184@,gmail.com Faculdade de Conchas (FACON)

Raquel Rodrigues Schwarz E-mail: rsschwarz@hotmail.com Faculdade de Conchas (FACON)

Ricardo Alexandre Marangoni E-mail: ramarangoni@hotmail.com Universidade Federal do Paraná (UFPR)

\begin{abstract}
RESUMO
Esta pesquisa tem por objetivo apresentar as principais dificuldades dos diretores de escola e compreender as formas de enfrentamento. A sua realização articula três vertentes: a primeira, associada à legislação municipal; a segunda, corresponde aos autores ligados à gestão educacional; a terceira, a aplicação de um questionário. Após a Análise de Conteúdo, os resultados indicaram que as principais dificuldades do diretor se ligam à gestão de pessoas e à falta de comprometimento dos profissionais. Os pesquisados apontaram a importância do diálogo, trabalho diferenciado e em equipe e investimento em formação, como formas de enfrentamento das dificuldades. A atuação do diretor como mediador das relações na escola é a sua principal atribuição.
\end{abstract}

PALAVRAS-CHAVE: Diretor de escola. Atribuições do diretor. Dificuldades e enfrentamentos do diretor.

\section{ABSTRACT}

The objective of this research is to understand the main difficulties faced by school principals and to understand the forms of coping. Its implementation articulates three aspects: the first one, associated with municipal legislation, the second, corresponds to authors related to educational management, the third, the application of a questionnaire. After analyzing the content, the results indicated that the main difficulties of the director are related to the management of people and the lack of commitment of the professionals. The interviewees pointed out the importance of dialogue, differentiated work and the team and investment in training, as ways of coping with difficulties. The principal's role as a mediator of relationships in school is his primary assignment.

KEYWORDS: School principal. Attributions of the director. Difficulties and confrontations of the director.

\section{RESUMEN}

Esta investigación tiene por objetivo conocer las principales dificultades de los directores de escuela y comprender las formas de enfrentamiento. Su realización articula tres vertientes: la primera, asociada a la legislación municipal, la segunda, corresponde a los autores vinculados a la gestión educativa, la tercera, la aplicación de un cuestionario. Después del análisis de contenido, los resultados indican que las principales dificultades del director se ligan a la gestión de las personas ya la falta de compromiso de los profesionales. Los investigadores apuntaron la importancia del diálogo, trabajo diferenciado y en equipo e inversión en formación, como formas de enfrentamiento de las dificultades. La actuación del director como mediador de las relaciones en la escuela es su principal atribución.

PALABRAS-CLAVE: Director de escuela. Atribuciones del director. Dificultades y enfrentamientos del director. 


\section{INTRODUÇÃO}

Esta pesquisa surgiu a partir do estágio supervisionado realizado no segundo semestre de 2016, no curso de Pedagogia de uma faculdade do interior paulista. Durante o desenvolvimento do estágio, observamos vários aspectos da rotina escolar, porém, foi a atuação do diretor que mais chamou a nossa atenção. A vivência e as discussões realizadas na disciplina de Gestão Educacional despertaram-nos o interesse pela investigação de duas questões centrais: (1) Quais as principais dificuldades no desenvolvimento do trabalho de diretor de escola? (2) Como enfrentam as dificuldades apontadas?

Logo, os nossos objetivos foram: (i) analisar as atribuições do diretor, de acordo com a legislação municipal e a literatura especializada; (ii) conhecer as principais dificuldades enfrentadas pelos diretores; (iii) investigar os caminhos por eles adotados para seu enfrentamento.

A revisão de literatura indicou-nos que existe uma vasta produção com diferentes abordagens acerca da temática. Selecionamos as obras de Lück (2009), Russo (2009), Abdian; Oliveira; Jesus (2013); Hojas; Abdian (2015) e Marangoni (2017) para embasar a discussão sobre o trabalho do diretor de escola.

Analisando a gestão do cotidiano escolar, Lück (2009, p. 137) afirma que é possível "[...] verificar que ela não é, de fato e plenamente o espaço onde se realizam as propostas oficiais da educação, embora se pretenda que o seja". A afirmação da autora, nos leva a inferir que a escola se inscreve em movimentos oficiais e não oficiais. As questões que orientam o nosso estudo fazem parte desses movimentos não oficiais e revelam-se pertinentes, por compreender o trabalho do diretor a partir do que dizem.

\section{AS ATRIBUIÇÕES DO DIRETOR DE ESCOLA}

\subsection{A perspectiva da legislação municipal}

Os diretores de escola têm suas atribuições reguladas na Lei Complementar $n^{\circ} 246$, de 27 de abril de 2016 que "dispõe sobre o plano de carreira e a remuneração dos profissionais da Educação Básica do Município de Conchas e dá outras providências”, a qual preconiza: 
II. Administrar o pessoal e os recursos materiais e financeiros da escola, tendo em vista o cumprimento dos fins educacionais;

III. Cumprir e assegurar o cumprimento das disposições legais e das diretrizes da política educacional nacional e do departamento de educação de Conchas;

IV. Controlar a frequência diária dos servidores e atestar a presença nos documentos relativos ao pagamento do pessoal;

V. Assegurar as atividades e o cumprimento dos dias e horas letivos estabelecidos em calendário escolar;

VI. Zelar pelo plano de trabalho do corpo docente;

VII. Prover meios para a execução dos processos de recuperação aos alunos de menor rendimento escolar;

VIII. Promover a articulação da escola com as famílias e comunidade;

IX. Dirigir a escola, cumprindo e fazendo cumprir as leis, regulamentos, o calendário escolar, as determinações superiores e as disposições do plano municipal de educação, de modo a garantir a consecução dos objetivos do processo educacional;

$\mathrm{X}$. Representar o estabelecimento perante as autoridades escolares e municipais;

XI. Presidir as reuniões e festividades promovidas pela escola;

XII. Garantir a circulação e o acesso de toda informação de interesse da comunidade e ao conjunto de servidores e alunos da escola;

XIII. Tomar as providências necessárias para eliminar a evasão e a repetência de aluno;

XIV. Dirigir, no âmbito da escola, as atividades de planejamento, avaliação e desenvolvimento profissional dos docentes;

XV. Acompanhar o processo de desenvolvimento de habilidade e competência dos alunos, informando aos pais sobre seus resultados;

XVI. Elaborar estudos, levantamentos qualitativos e quantitativos necessários para o aprimoramento das ações educativas na escola;

XVII. Elaborar, acompanhar e avaliar os planos, programas e projetos voltados para o desenvolvimento do ensino e aprendizagem na escola, garantindo melhoramento contínuo nos aspectos pedagógicos, administrativos, financeiros, de pessoal e de recursos materiais;

XVIII. Comunicar ao conselho tutelar todos os casos de maus tratos, negligência, evasão e baixa frequência relativo aos alunos, garantindo os direitos à proteção, contidos no estatuto da criança e do adolescente;

XIX. Executar outras tarefas correlatas, relacionadas à gestão democrática, determinada pelo superior imediato (CONCHAS, 2016).

A análise de parte da legislação municipal permite constatar que as atribuições destinadas ao diretor de escola contemplam questões pedagógicas e burocrático-administrativas. A nossa reflexão indica uma ênfase nas últimas. Alguns verbos utilizados no referido artigo, sugerem que cabe ao diretor dirigir e controlar as ações na escola, de modo que ele assuma um papel de implementador e fiscalizador das políticas educacionais.

Nossas observações assistemáticas indicam que o diretor dedica a maior parte do tempo às questões administrativas, o que dificulta sua aproximação das questões pedagógicas. Corroborando, Marangoni (2017, p. 46), afirma que "as tarefas burocráticas do diretor distanciavam-no do processo pedagógico, restando a ele agir como um técnico, preenchedor de papéis, ou como um transgressor, que dá um jeito de "burlar" o burocrático e priorizar a dimensão pedagógica". 


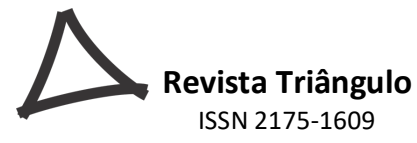

As tarefas burocrático-administrativas da escola requerem do diretor o conhecimento técnico para desenvolvê-las, porém, o seu trabalho não pode ser sintetizado às questões técnicas. Alertamos para o papel político de sua ação.

As atribuições descritas na lei são muitas. Apesar de reconhecermos que o diretor é o responsável pela unidade escolar, parece-nos que a quantidade de afazeres prescritos na lei tem dificultado o desenvolvimento do seu trabalho.

\subsection{A perspectiva da literatura educacional}

A complexidade que envolve as atribuições do diretor escolar está relacionada às formas de administrar a escola. Essa discussão não é recente e, alguns autores (RIBEIRO, 1960; LOURENÇO FILHO, 1963/2007; ALONSO, 1976 apud ABDIAN; OLIVEIRA; JESUS, 2013), principalmente nas décadas de 1960 e 1970, fundamentaram seus estudos na Teria Geral da Administração, aproximando a administração de uma escola à administração de uma empresa.

Convém ressaltar que não é objetivo desta pesquisa adentrar nessa discussão, pois isso requer uma análise mais profunda e minuciosa. Apenas salientamos que, Anísio Teixeira (1968), citado por Abdian; Oliveira; Jesus (2013), já advogou a ideia de que a administração escolar não pode ser comparada a administração de empresas e que ao administrador da escola cabe mediar e não liderar.

Dito isto, passamos a expor as atribuições concebidas pelos teóricos ao diretor escolar. Para Lourenço Filho (1963/2007), abordado por Marangoni (2017), cabe ao diretor: planejar e programar; dirigir e coordenar; comunicar e inspecionar; controlar e pesquisar. Marangoni (2017), se afasta dessa abordagem.

De acordo com Alonso (1976), mencionado por Hojas; Abdian (2015, p. 204), incumbe ao diretor ser atuante na tomada de decisões e nos diversos níveis da organização escolar, responder pelas ações e proposições junto aos órgãos superiores, trazendo informações para que sejam discutidas e aplicadas dentro do contexto escolar.

Diferentemente de Alonso (1976), Teixeira (1968) citado por Marangoni (2017) discorre sobre a direção de escola mudar o olhar da administração de empresa para a administração escolar, posicionando o diretor como mediador: “[...] se alguma vez a função de direção faz-se uma função de serviço e não de mando, esse é o caso do administrador escolar" (TEIXEIRA, 1968 apud MARANGONI, 2017, p. 34). 
A partir dos anos 1980, fica mais explícito a crítica ao modelo até então vigente que comparava a escola com a empresa e o administrador escolar com o administrador empresarial. As abordagens da área expressaram a mudança de perspectiva, como podemos observar nos estudos de Paro (1986), aludido por Abdian; Oliveira; Jesus (2013), o qual atribuiu que:

[...] a função do diretor seja a de mobilizar o grupo na luta pela democratização da sociedade e por uma administração/direção coletiva. Neste sentido, enfatiza-se o caráter político da função, à contracorrente do que ocorreu nas décadas anteriores, quando se supervalorizou a função técnica do diretor de escola (p. 982).

Marangoni (2017) também defende que o diretor precisa assumir a "função de articulador e não de líder, na medida em que favorece a participação de todos na tomada de decisão" (p. 37). Assim, diante das situações que se apresentam no cotidiano escolar, o diretor precisa mediar eventuais problemas, de modo que a tomada de decisão seja feita com a participação de todos.

\subsection{As principais dificuldades do diretor de escola}

A busca pela literatura que discorre sobre as dificuldades enfrentadas pelos diretores, direcionou-nos ao artigo de Russo (2009), que ao tratar desta temática afirma que são poucas as publicações que abordam os desafios da gestão de forma mais específica, tendo em vista que "são questões que emergem quando se adentra ao empírico da escola [...]” (p. 457).

Nossa intenção é adentrar ao empírico da escola, e, justamente, questionar os diretores sobre os principais problemas que enfrentam e como lidam com eles. Já acompanhamos a rotina escolar, quando do desenvolvimento do estágio supervisionado e, salientamos a necessidade de o diretor conhecer a realidade e a comunidade em que a escola está inserida.

Assinala Russo (2009), que são inúmeros os problemas apontados pelos diretores, no entanto, alguns são comuns à maioria, podendo destacar os principais:

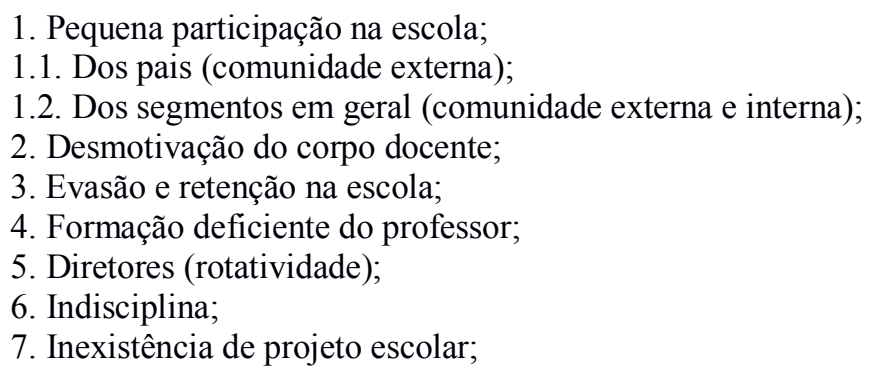



8. Ausência de resultados das aulas de reforço;
9. Danos ao patrimônio da escola;
10. Falta de funcionários;
11. Resultados do PEC dos docentes (RUSSO, 2009, p. 459).

Observamos que as dificuldades têm origens diferentes, porém, todas elas impactam a unidade escolar e interferem no processo de ensino e aprendizagem.

Hojas e Abdian (2015), abordam que a falta de formação para o ocupante do cargo de diretor, pode resultar em desafios para este e para a escola. As autoras argumentam que "independentemente da forma de provimento ao cargo" para assumir a função é necessário a experiência como professor, porém, a formação específica para o diretor, em exercício, se dá por meio da formação continuada, que por sua vez são realizadas pelos órgãos centrais, e são orientados no gerencialismo empresarial, ou seja, "privilegiam os aspectos tecnocráticos da função do diretor de escola em detrimento de questões sociais e educacionais [...]" (p. 208).

Outro desafio que podemos mencionar, é a comunicação, ou a falta dela, dentro da escola. Lourenço Filho (2007), abordado por Abdian; Oliveira; Jesus (2013, p. 980), esclarece que muitos problemas podem emergir por falta de informação entre "dirigentes e subordinados". A comunicação precisa acontecer entre todos os envolvidos na escola e em todas as direções "de cima para baixo e de baixo para cima" para que ocorra o entendimento entre os que trabalham e assim possam exercer suas funções.

Embora os problemas apontados pelos autores mencionados, sejam, em certa medida, comuns aos diretores, os meios empregados para superá-los não são os mesmos, pois de acordo com Lück (2009, p. 129), "nenhuma escola é igual a outra, embora possam ser parecidas, por expressarem elementos comuns".

Portanto, discutir as dificuldades e as formas de enfrentamento, se torna relevante, no sentido de corroborar com as ações de outros diretores, que estejam enfrentando situações semelhantes.

\section{METODOLOGIA}

A pesquisa foi desenvolvida a partir de três etapas complementares: a primeira, apoiada na análise da legislação municipal; a segunda, baseada no estudo dos autores da área; a terceira, assentada na aplicação de questionários. Participaram quatro diretores de escola do município de Conchas/SP e, os dados coletados foram submetidos à Análise de Conteúdo (MORAES, 1999). 


\subsection{A caracterização das escolas}

Foram selecionadas quatro escolas municipais de Conchas/SP. Todas estão localizadas na zona urbana e serão designadas como Escola 1 (E1), Escola 2 (E2), Escola 3 (E3) e Escola 4 (E4).

\subsubsection{Escola 1}

A E1 encontra-se localizada no perímetro urbano da cidade de Conchas e atende os Anos Finais do Ensino Fundamental e a Educação de Jovens e Adultos. A instituição dispõe de quinze salas de aula, sala de diretoria, sala dos professores, laboratório de informática, quadra de esportes coberta, cozinha, refeitório, cantina, sala de leitura, banheiros, sala de secretaria, despensa, pátio descoberto e ambiente para recreação.

Ela possui os órgãos colegiados formados, tais como: Conselho de Escola, Associação de Pais e Mestres e Grêmio Estudantil. É através dos órgãos mencionados e reuniões bimestrais, que a escola mantém o diálogo com a comunidade. Há também o Atendimento Educacional Especializado (AEE), sala especialmente equipada para atender a demanda de alunos, que pertencem a educação inclusiva.

Em relação ao mobiliário, a instituição possui computadores administrativos, computadores para os discentes, TV, DVD, impressora, aparelho de som, projetor multimídia (Datashow) e acesso à internet.

Vários projetos são desenvolvidos pela escola. Um exemplo é o Projeto Mais Educação, que oferece estudos de reforço fora do horário de aula regular, cursos, oficinas, lazer e cultura aos alunos, dentre outros projetos.

\subsubsection{Escola 2}

A E2 também se encontra no perímetro urbano e atende alunos da Educação Infantil (creche e pré-escola).

A escola conta com nove salas de aula, uma biblioteca destinada aos professores e monitores, uma biblioteca destinada aos alunos, com jogos e brinquedos que o professor pode utilizar em suas aulas, uma sala de artes cênicas, com fantoches e espaço para contação de histórias.

A área de lazer da escola contém dois parques menores, um parque maior e um bosque com área verde. A escola possui também uma quadra, corredores espaçosos que podem ser utilizados para

\begin{tabular}{l|c|c|c|c|c|}
\hline C Revista Triângulo & Uberaba, Minas Gerais & v. 12 & n. 2 & p. 14-31 & 2019
\end{tabular}


apresentações de danças, músicas e de teatros, área de alimentação grande, que funciona também como um espaço de aprendizagem, com apresentações, brincadeiras, reuniões; o espaço é multifuncional. Finalmente, dispõe de uma sala de TV, onde são realizados vários tipos de atividades pelo professor.

Nessa escola tem a sala de AEE, com um horário de atendimento para cada aluno que faz parte da inclusão, sendo que também recebe de outras escolas para atendimento com professora especializada. Há o atendimento com psicólogo e fonoaudiólogo que acompanham e orientam os trabalhos.

\subsubsection{Escola 3}

A E3 está localizada na área central da cidade, cercada de comércios, o que faz com que a movimentação no seu entorno seja intensa e constante. Atende alunos dos anos iniciais do Ensino Fundamental.

Embora existam muitas residências, nota-se que a escola recebe diariamente grande quantidade de alunos, que utilizam o transporte público escolar.

A E3 dispõe de treze salas de aula, uma biblioteca, uma "casinha de madeira" com duas salas para o Projeto Mais Educação, uma sala de professores, uma sala de direção, uma cozinha; uma quadra de esporte, uma sala de recursos AEE, uma sala de informática, uma secretaria e uma sala de coordenação.

\subsubsection{Escola 4}

A E4 está situada em um bairro mais afastado do centro da cidade, uma região com menor nível socioeconômico. Essa escola atende alunos dos anos iniciais do Ensino Fundamental.

O espaço escolar está organizado com onze salas de aula, sala de diretoria, sala de professores, cozinha e berçário. Dispõe de computadores administrativos, TV, DVD, impressora, aparelho de som, projetor multimídia (Datashow), câmera fotográfica e filmadora.

A instituição dispõe ainda de um espaço de alimentação e ambiente para recreação. 


\subsection{Os participantes da pesquisa}

Fizeram parte desta pesquisa quatro diretores de escolas públicas municipais, que atendem alunos da Educação Infantil, Ensino Fundamental (Anos Iniciais e Anos Finais) e Educação de Jovens e Adultos (EJA).

\subsection{A coleta de dados}

A coleta de dados ocorreu a partir de três vertentes. A primeira, associada à legislação municipal; a segunda, corresponde aos autores ligados à gestão educacional; a terceira, a aplicação de um questionário.

Em relação ao questionário, este apresenta questões fechadas e abertas. Com as questões fechadas, desejamos conhecer o perfil dos participantes e, com as questões abertas, analisar as principais atribuições do diretor, suas dificuldades e formas de enfrentamento.

\subsection{Procedimentos de Análise}

A Análise de Conteúdo foi baseada em Moraes (1999), que orientou a descrição e compreensão dos dados coletados. As etapas realizadas foram: (1) pré-leitura das respostas dos participantes; (2) organização das tabelas; (3) criação de categorias a partir das respostas; (4) interpretação.

As categorias foram produzidas a partir do agrupamento de dados considerando a semelhança entre eles. As etapas acima revelam que a nossa análise se ampara na perspectiva qualitativa.

\section{APRESENTAÇÃO E ANÁLISE DOS DADOS}

\subsection{O perfil dos participantes}

São participantes da pesquisa quatro diretores de escolas públicas municipais, designados como Diretor 1 (D1), Diretor 2 (D2), Diretor 3 (D3) e Diretor 4 (D4).

Partindo das respostas, quanto ao perfil do grupo pesquisado, 100\% são do sexo feminino, o que mostra a grande presença feminina no cargo de diretor escolar.

\begin{tabular}{l|l|l|l|l|l|} 
(C) Revista Triângulo & Uberaba, Minas Gerais & v. 12 & n. 2 & p. $14-31$ & 2019
\end{tabular}


Observamos que a maior parte das participantes tem idade entre 50 e 54 anos, restando apenas um pesquisado com 35 anos. Isso demonstra que essa função está sendo ocupada por pessoas consideradas mais experientes, e com maior tempo de exercício profissional.

Quanto à raça, 100\% das participantes se declararam branca.

No que se refere à formação acadêmica, 100\% das diretoras participantes da pesquisa fizeram Pedagogia, sendo que uma delas cursou também Letras e outra cursou Sociologia.

Sobre a Pós-Graduação, $100 \%$ das diretoras afirmaram possuir esse curso. A diretora designada como D1 possui Psicopedagogia, Libras e Neuropsicopedagogia, a D2 tem Arte Educação, a D3 possui em Língua Portuguesa e a D4, Psicopedagogia Institucional e Clínica e Arte Educação.

Em relação ao tempo em que atuam na gestão escolar, os participantes responderam: o D1 apresenta 2 anos, o D2 e D3 apresentam 3 anos e o D4 apresenta 4 anos. Salientamos que todos acessaram o cargo de diretor por indicação política.

\subsection{Apresentação e análise dos dados}

O questionário respondido pelo grupo pesquisado apresenta questões abertas. Por meio delas, expressaram alguns aspectos relacionados ao seu trabalho. Os dados foram organizados em quadros e, posteriormente, ocorreu a criação de categorias de análise. Como dissemos anteriormente, utilizamos a Análise de Conteúdo (MORAES, 1999). Seguem, no quadro 1, as respostas da questão 7, apontadas pelos diretores (D1 a D4).

Quadro 1: Questão 7 - Na sua opinião, quais são as principais atribuições do diretor de escola?

\begin{tabular}{|c|l|c|}
\hline Diretor & \multicolumn{1}{|c|}{ Respostas dos participantes } & Escola \\
\hline D1 & $\begin{array}{l}\text { Administrar a escola dentro de vários aspectos como: finanças } \\
\text { da escola (prestar contas), conduzir a elaboração do PPP; } \\
\text { identificar as necessidades da escola (buscar soluções); } \\
\text { acompanhar o avanço na aprendizagem dos alunos; conhecer a } \\
\text { legislação, gerenciando professores, funcionários e } \\
\text { atendimentos dos alunos e famílias. } \\
\text { Derenciar e articular o trabalho de professores, orientadores e } \\
\text { funcionários; prestar contas à comunidade nas reuniões de } \\
\text { trabalho que está sendo desenvolvido no ambiente escolar; } \\
\text { manter a manutenção da escola, limpa e organizada, etc. }\end{array}$ & E2 \\
\hline
\end{tabular}




\begin{tabular}{|c|c|c|}
\hline Diretor & Respostas dos participantes & Escola \\
\hline D3 & $\begin{array}{l}\text { A direção da escola é o núcleo executivo que organiza, } \\
\text { superintende, executa e controla todas as atividades } \\
\text { desenvolvidas no âmbito da unidade escolar. E zela pelas } \\
\text { melhores condições de aprendizagem tanto emocional como } \\
\text { cognitiva. }\end{array}$ & $\mathbf{E 3}$ \\
\hline D4 & $\begin{array}{l}\text { Acompanhar o cotidiano da instituição, em especial, da sala de } \\
\text { aula e o avanço da aprendizagem dos alunos; manter a } \\
\text { comunicação com os pais e atendê-los quando necessário; ser } \\
\text { parceiro do coordenador pedagógico na gestão da aprendizagem } \\
\text { dos alunos; cuidar das finanças e prestar contas à comunidade; } \\
\text { identificar as necessidades, traçar metas e elaborar um plano de } \\
\text { ação; conduzir a elaboração do PPP; gerenciar e articular o } \\
\text { trabalho dos professores e funcionários; delegar tarefas para o } \\
\text { bom funcionamento da instituição. }\end{array}$ & E4 \\
\hline
\end{tabular}

Fonte: Autores, 2018.

No quadro 2, seguem as categorias e as frequências.

Quadro 2 - Categorias de análise

\begin{tabular}{|l|c|}
\hline \multicolumn{1}{|c|}{ Categorias } & $N^{{ }^{o}}$ \\
\hline Conduzir a elaboração do PPP & 2 \\
\hline Acompanhar a aprendizagem dos alunos & 3 \\
\hline Gerenciar o trabalho dos docentes e funcionários & 3 \\
\hline Cuidar das finanças da escola e prestar contas & 2 \\
\hline Conhecer a legislação & 2 \\
\hline Prestar contas à comunidade & 2 \\
\hline Atender os pais e alunos & 4 \\
\hline Identificar as necessidades da escola/manutenção & 1 \\
\hline Delegar tarefas & 2 \\
\hline
\end{tabular}

Fonte: Autores, 2018. Obs.: Os totais indicam o número de respostas e não o de participantes. 
A nossa análise se pautará nas três categorias de maior frequência, sendo: "identificar as necessidades da escola/manutenção", "acompanhar a aprendizagem dos alunos” e "gerenciar o trabalho dos docentes e funcionários".

Os diretores pesquisados apontaram como parte das suas atribuições gerenciar a escola, o trabalho dos docentes e funcionários e, subsidiar o aprendizado dos alunos. Constata-se que tais atividades estão prescritas na legislação municipal n 246/16, em seu artigo 14, inciso II "administrar o pessoal e os recursos materiais e financeiros da escola [...]", bem como no inciso VI "zelar pelo plano de trabalho do corpo docente" e "acompanhar o processo de desenvolvimento de habilidades e competências dos alunos [...], no inciso XV.

Corrobora com esse entendimento Abdian; Oliveira; Jesus (2013, p. 980) ao salientar que compete ao diretor dirigir e coordenar a escola ao passo que esta funcione no devido tempo e forma. De fato, o diretor precisa se ocupar da gestão dos recursos humanos, como aponta a legislação municipal, de acordo com as demandas oriundas do cotidiano escolar.

No quadro 3, seguem as respostas da questão 8.

Quadro 3: Questão 8 - Quais as principais dificuldades no desenvolvimento de seu trabalho?

\begin{tabular}{|c|l|c|}
\hline Diretor & \multicolumn{1}{|c|}{ Respostas dos participantes } & Escola \\
\hline D1 & $\begin{array}{l}\text { Por ser uma escola muito grande que envolve muitos } \\
\text { funcionários, a maior dificuldade é na gestão de pessoas em } \\
\text { relação aos compromissos no trabalho, ou seja, pessoas que não } \\
\text { são comprometidas. }\end{array}$ & E1 \\
\hline D2 & $\begin{array}{l}\text { Quando encontro profissionais que esquecem que saíram de } \\
\text { casa para trabalhar. }\end{array}$ & E2 \\
\hline D3 & $\begin{array}{l}\text { Como diretora de escola pública, a gestão de pessoas e } \\
\text { profissionais da educação, por se tratar de serviço público a } \\
\text { grande maioria são efetivos em seus cargos e quando não são } \\
\text { fazemos a gestão direta na escola, mas, o RH é competência da } \\
\text { prefeitura o que nos “amarra" a administração. }\end{array}$ & E3 \\
\hline D4 & $\begin{array}{l}\text { Defasagem na alfabetização; número elevado de baixo } \\
\text { rendimento em determinados descritores comprometendo as } \\
\text { provas externas; indisciplina e falta de interesse dos alunos; } \\
\text { baixa participação dos pais na vida escolar dos filhos. }\end{array}$ & E4 \\
\hline
\end{tabular}

Fonte: Autores, 2018. 
No quadro 4, seguem as categorias e as frequências.

Quadro 4 - Categorias de análise

\begin{tabular}{|l|c|}
\multicolumn{1}{|c|}{ Categorias } & $N^{{ }^{*}}$ \\
\hline Gestão de pessoas & 2 \\
\hline Indisciplina & 1 \\
\hline Baixa participação dos pais & 1 \\
Falta de comprometimento dos profissionais & 2 \\
\hline Defasagem na alfabetização & 1 \\
\hline Falta de interesse dos alunos & 1 \\
\hline Baixo rendimento nas provas externas & 1 \\
\hline
\end{tabular}

Fonte: Autores, 2018. Obs.: Os totais indicam o número de respostas e não o de participantes.

A nossa análise se pautará nas duas categorias de maior frequência, sendo: "gestão de pessoas" e "falta de comprometimento dos profissionais".

Como podemos observar, novamente vem à tona "gestão de pessoas", descrito na Lei Complementar $n^{\circ} 246 / 16$, inciso II. Segundo o relato do D1, uma dificuldade para o desenvolvimento do trabalho da direção escolar é: "por ser uma escola muito grande que envolve muitos funcionários, a maior dificuldade é na gestão de pessoas em relação aos compromissos no trabalho [...]". Particularmente, nossas observações assistemáticas durante a realização do estágio supervisionado, confirmam ser uma dificuldade gerir e organizar pessoas no ambiente escolar.

Outro fator exposto pelos diretores que atrapalha a gestão é a falta de comprometimento dos profissionais, que segundo Russo (2009, p. 466), está relacionado com a desmotivação do corpo docente e algumas das causas para esse problema são: descompromisso do professor com o trabalho de qualidade na escola pública e as leis flexíveis que permitem ausências indiscriminadas, o que prejudica consideravelmente a dinâmica da escola e, por conseguinte, o processo de ensinoaprendizagem. 
No quadro 5, seguem as respostas da questão 9.

Quadro 5: Questão 9 - Como enfrentam as dificuldades apontadas?

\begin{tabular}{|c|c|c|}
\hline Diretor & Respostas dos participantes & Escola \\
\hline D1 & $\begin{array}{l}\text { Através do diálogo e orientação registrada, sempre reforçando a } \\
\text { importância de ser uma equipe que pensa junto para atingir o } \\
\text { mesmo objetivo. }\end{array}$ & E1 \\
\hline D2 & $\begin{array}{l}\text { Converso com o profissional para tentar entender o porquê de } \\
\text { certas atitudes. }\end{array}$ & E2 \\
\hline D3 & $\begin{array}{l}\text { Tentando sempre a motivação da equipe e formação dos } \\
\text { mesmos para assim oferecermos uma melhor oferta de trabalhos } \\
\text { prestados. }\end{array}$ & $\mathbf{E 3}$ \\
\hline D4 & $\begin{array}{l}\text { Trabalhos diferenciados com alunos em defasagem, } \\
\text { individualmente ou em duplas; simulados em preparação para } \\
\text { as provas externas; formação com os professores e estudo em } \\
\text { HTPC das habilidades e competências em defasagem; projetos } \\
\text { institucionais: "Letras e números por toda parte", "Cultura da } \\
\text { Paz" e "A diferença que nos une"; convites frequentes aos pais } \\
\text { para participarem de eventos e atividades escolares juntamente } \\
\text { com seus filhos; recreio dirigido com jogos diversos, } \\
\text { amarelinhas e sempre que possível a presença do diretor ou vice- } \\
\text { diretor circulando nos intervalos; professores usando diferentes } \\
\text { estratégias despertando o interesse do aluno para que sinta } \\
\text { prazer em vir para à escola e sinta alegria em aprender. }\end{array}$ & E4 \\
\hline
\end{tabular}

Fonte: Autores, 2018.

No quadro 6, seguem as categorias e as frequências.

\section{Quadro 6 - Categorias de análise}

\begin{tabular}{|l|c|}
\hline \multicolumn{1}{|c|}{ Categorias } & $N^{{ }^{\boldsymbol{o}}}$ \\
\hline Diálogo & 2 \\
\hline Formação de professores & 2 \\
\hline Convite frequente aos pais & 1 \\
\hline Trabalho em equipe & 2 \\
\hline Simulados para as provas externas & 1 \\
\hline Trabalhos diferenciados com alunos & 2 \\
\hline
\end{tabular}




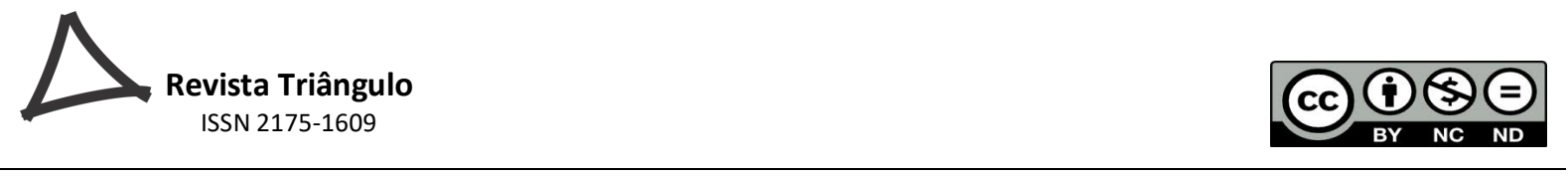

\begin{tabular}{|l|c|}
\hline Projetos institucionais & 1 \\
\hline Estudo em HTPC & 1 \\
\hline Recreio dirigido com jogos diversos & 1 \\
\hline
\end{tabular}

Fonte: Autores, 2018. Obs.: Os totais indicam o número de respostas e não o de participantes.

A nossa análise se pautará nas categorias de maior frequência, sendo: "diálogo", "formação de professores", "trabalho em equipe" e "trabalhos diferenciados com os alunos".

Observando a tabela acima, é possível constatar que um dos meios para superação das dificuldades apontadas se dá através da comunicação, previsto no inciso XII da Lei Complementar $\mathrm{n}^{\circ}$ 246/16 e como é mencionado por Lourenço Filho (2007 apud ABDIAN; OLIVEIRA; JESUS, 2013, p. 980), que ressalta que a ausência de comunicação entre os que atuam no ambiente escolar pode resultar em muitos problemas, assim, quando há o diálogo os conflitos são evitados ou amenizados.

Outra forma de enfrentar as dificuldades, segundo os diretores, é o investimento em formação de professores, fundamental para o desenvolvimento do trabalho pedagógico. Novamente a legislação ratifica essa ideia ao descrever no texto legal "dirigir no âmbito da escola, as atividades de planejamento, avaliação e desenvolvimento profissional dos docentes" (CONCHAS, 2016). Normalmente, essa formação se dá nas reuniões de HTPC (Hora de Trabalho Pedagógico Coletivo) mediada pelo professor coordenador pedagógico.

Os diretores também afirmaram que uma das formas de superar as dificuldades do desenvolvimento do seu ofício é com o trabalho em equipe, como podemos verificar no discurso do D1: "sempre reforçando a importância de ser uma equipe que pensa junto para atingir o mesmo objetivo" e também na fala do D3: "tentando sempre a motivação da equipe". Essas narrativas revelam que o diretor precisa de uma equipe engajada para o mesmo propósito. Ao olharmos novamente para a literatura observamos que o trabalho de diretor, segundo Lourenço Filho (2007 apud MARANGONI, 2017, p. 34), abrange "dirigir e coordenar significa fazer, o que implica na divisão de tarefas, de responsabilidades e de níveis de autoridade", sendo necessário uma equipe que respalde as ações da direção inclusive para resolução das dificuldades.

No que tange aos "trabalhos diferenciados com os alunos", observamos que essa ação com o propósito de superar problemas relacionados à aprendizagem, se aproxima do que a legislação municipal estabelece como atribuições do diretor no seu inciso VII: "prover meios para execução dos processos de recuperação aos alunos de menor rendimento escolar" (CONCHAS, 2016). Embora o 
diretor não esteja à frente da sala de aula, sua responsabilidade com o provimento dos meios com os quais os professores poderão trabalhar a recuperação dos alunos que necessitarem é fundamental.

No quadro 7, seguem as respostas da questão 10 .

Quadro 7: Questão 10 - Existe algum suporte da Secretaria da Educação, da Comunidade, da Equipe Escolar na solução ou encaminhamento dessas dificuldades. Justifique.

\begin{tabular}{|c|l|c|}
\hline Diretor & \multicolumn{1}{|c|}{ Respostas dos participantes } & Escola \\
\hline D1 & $\begin{array}{l}\text { Sim, a Secretaria está sempre divulgando e providenciando, } \\
\text { concursos, certames, listas de professores substitutos, porém, } \\
\text { ainda não é o suficiente. Os professores selecionados muitas } \\
\text { vezes não acompanham a proposta da escola (conteúdo) e isso } \\
\text { acaba parando o processo de aprendizagem. }\end{array}$ & E1 \\
\hline D2 & $\begin{array}{l}\text { Sim, na Secretaria da Educação encontramos todo o apoio } \\
\text { necessário para qualquer dificuldade que necessita de maior } \\
\text { atenção que ocorre no ambiente escolar. }\end{array}$ & E2 \\
\hline D3 & $\begin{array}{l}\text { Sim. Porque temos o mesmo objetivo e as perguntas que sempre } \\
\text { norteiam nossas decisões e discussões são: o que é melhor para } \\
\text { o aluno? O que menos prejudicará? O que vai beneficiar a } \\
\text { aprendizagem? }\end{array}$ & E3 \\
\hline D4 & $\begin{array}{l}\text { Sim, existe o suporte da Secretaria da Educação no que se refere } \\
\text { às formações aos professores vindas da Secretaria; apoio da } \\
\text { supervisora nas preparações dos planejamentos semestrais e até } \\
\text { mesmo em orientações para os HTPC. } \\
\text { Contamos ainda com avaliações da fonoaudióloga e da } \\
\text { psicóloga, encaminhando, quando necessário, os casos com } \\
\text { maiores dificuldades, ao acompanhamento desses profissionais } \\
\text { do AMI, para com essas crianças. } \\
\text { Por fim, temos ainda as salas de AEE às crianças em que os pais } \\
\text { apresentam laudos de especialistas constatando alto nível de } \\
\text { falta de concentração ou algum outro problema mais sério. }\end{array}$ & E4 \\
\hline
\end{tabular}

Fonte: Autores, 2018.

No quadro 8, seguem as categorias e as frequências.

Quadro 8 - Categorias de análise

\begin{tabular}{|l|c|}
\hline \multicolumn{1}{c|}{ Categorias } & $N^{{ }^{\boldsymbol{o}}}$ \\
\hline Professores substitutos & 1 \\
\hline Formação de professores & 1 \\
\hline
\end{tabular}




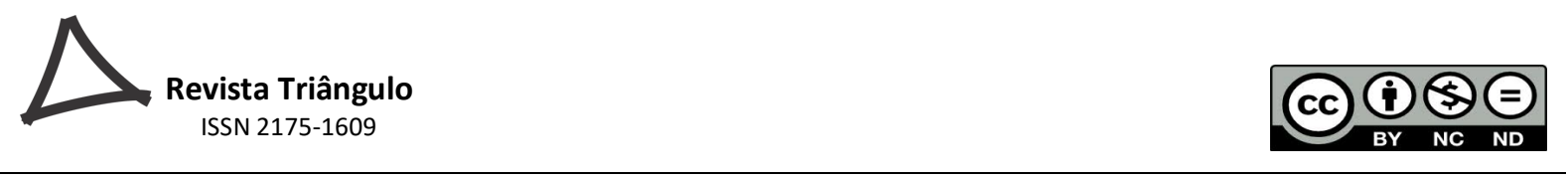

\begin{tabular}{|l|c|}
\hline Salas AEE - Atendimento Educacional Especializado & 1 \\
\hline Concursos e Certames & 1 \\
\hline Auxílio nos planejamentos semestrais & 1 \\
\hline Orientações para os HTPC & 1 \\
\hline Apoio com profissionais da saúde & 1 \\
\hline
\end{tabular}

Fonte: Autores, 2018. Obs.: Os totais indicam o número de respostas e não o de participantes.

As respostas dos participantes indicaram que a Secretaria Municipal da Educação oferece suporte no enfrentamento das dificuldades. O D1 salienta que o suporte "ainda não é suficiente". Como as justificativas apontaram para categorias com frequências equivalentes, preferimos não discorrer sobre elas. Apenas, chamamos a atenção para o fato de que o acesso ao cargo de diretor pela via da indicação política, pode causar o receio de os diretores dizerem o que realmente pensam. Por ora, não vamos realizar um aprofundamento nessa direção.

\section{CONSIDERAÇÕES FINAIS}

Esta pesquisa buscou compreender as dificuldades do diretor de escola e suas formas de enfrentamento, a partir de três etapas complementares. A análise documental nos permitiu compreender que embora o objetivo principal da gestão seja o pedagógico, o funcionamento da escola exige do diretor uma dedicação às questões administrativas e burocráticas. Sobre este aspecto, concluímos que as dimensões pedagógicas, administrativas e burocráticas são indissociáveis.

A literatura educacional mostrou que os primeiros escritos (1930) sobre a Administração Escolar sofreu forte influência da Teoria Geral da Administração. Grosso modo, foi reforçado que o papel do diretor se restringia a dimensão técnica. A partir dos anos 1980, outros autores entram em cena e questionam a produção anterior. Começa a ser enfatizado fortemente a dimensão política do papel do diretor. Apesar de a pesquisa não se aprofundar nessa direção, compreendemos que há um reposicionamento da figura do diretor; aqueles que defendem o papel de líder e, aqueles que defendem o de mediador. O último parece-nos ser o mais adequado, tendo em vista a construção de relações de poder horizontais na escola.

Em relação as principais dificuldades mencionadas pelos diretores estão: a gestão de pessoas e a falta de comprometimento dos profissionais. As formas de enfrentamento relacionam-se: ao 
diálogo, à formação de professores, ao trabalho em equipe e ao trabalho diferenciado com os alunos. Portanto, os resultados indicam a necessidade de uma revisão das políticas educacionais, priorizando maior investimento em formação e valorização dos profissionais da educação. Também, apontamos para a urgência de se questionar as condições concretas e objetivas das quais o diretor realiza o seu trabalho.

\section{REFERÊNCIAS}

ABDIAN, G. Z.; OLIVEIRA, M. E. N.; JESUS, G. Função do diretor na escola pública paulista: mudanças e permanências. Educação \& Realidade. Porto Alegre, v. 38, n. 3, p. 977-998, jul./set. 2013.

CONCHAS (Município). Lei Complementar $\mathbf{n}^{\circ}$ 246, de 27 de abril de 2016. Dispõe sobre o plano de carreira e remuneração dos profissionais da Educação Básica do município de Conchas e dá outras providencias. Conchas, 2016.

HOJAS, V. F.; ABDIAN, G. Z. Perfil do diretor da escola pública estadual paulista. Educação. Santa Maria. v. 40, n. 1, p. 201-214, jan./abr. 2015.

LÜCK, H. Dimensões de gestão escolar e suas competências. Curitiba: Positivo, 2009.

MARANGONI, R. A. Gestores escolares: representações e práticas. Curitiba: CRV, 2017.

MORAES, R. Análise de conteúdo. Revista Educação. Porto Alegre, v. 22, n. 37, p. 7-32, 1999.

RUSSO, M. H. Problemas centrais da gestão na escola pública e sua incidência na prática cotidiana segundo os gestores. RBPAE. v. 25, n. 3, p. 455-471, set./dez. 2009.

\begin{tabular}{|l|l|}
\hline & Recebido em: 23 Ago. 2018 \\
\hline & Aprovado em: 24 Abr. 2019 \\
\hline
\end{tabular}

